\title{
CORRIGENDUM
}

\section{taking the right seriously}

luís de sousa and riccardo marchi

doi: $10.1057 /$ eps.2011.63

Correction to: European Political Science (2010) 9, 446-453.

doi: $10.1057 /$ eps.2010.74

Luís de Sousa and Riccardo Marchi would like to acknowledge that an earlier, slightly different version of the review on Mabel Berezin's 'Illiberal Politics in Neoliberal times: Culture, Security and Populism in the New Europe' (London, Cambridge University Press, 2009) was previously published in e-Extreme, the electronic newsletter of the ECPR-Standing Group on Extremism \& Democracy. The authors are grateful to the editors of e-Extreme for their co-operation in making it more widely available through its publication in EPS Reviews. 